\title{
UMA ANÁLISE DA HISTÓRIA DO BRASIL PELA ECONOMIA POLÍTICA DOS SISTEMAS-MUNDO
}

\author{
AN ANALYSIS OF THE HISTORY OF BRAZIL BY THE \\ POLITICAL ECONOMY OF WORLD-SYSTEMS
}

Rosângela de Lima Vieira

Pós-doutora em Economia (Universidade Federal de Santa Catarina/Brasil)

Professora na Universidade Estadual Paulista (São Paulo/Brasil).

E-mail: rosangela_vieira@uol.com.br. 


\section{RESUMO}

O presente estudo pretende demonstrar que a análise da Economia Política dos Sistemas-Mundo (EPSM) tem contribuições significativas para uma reflexão da realidade atual, em especial do Brasil. A EPSM desenvolve sua abordagem a partir da perspectiva sistêmica, a qual tem por elementos basilares: uma análise histórica de longa duração; a interdisciplinaridade; as inter-relações entre os aspectos políticos, econômicos, sociais e culturais; e a divisão internacional em centro, semiperiferia e periferia. O principal objetivo do artigo consiste em explicitar que nossa história ao longo de cinco séculos é de subordinação aos interesses do centro de acumulação capitalista. Muito embora o centro venha se deslocando ao longo desses séculos, a condição de periferia, na maior parte do tempo, e de semiperiferia, em durações temporais mais curtas, persiste. A história tradicional, embora muitas vezes tenha tentado buscar as relações e inter-relações entre os interesses do capital e os ibéricos com suas colônias/ex-colônias, não possibilitou um aprofundamento da afinidade dessa realidade histórica. Por sua vez, a abordagem da EPSM tem uma contribuição incontestável para inovar nessas análises. As "Grandes Navegações” ocorreram na conjuntura da hegemonia das cidades italianas. A colonização empreendida por Portugal foi atrelada de forma visível aos interesses holandeses. A coroa portuguesa posteriormente conectou-se aos negócios britânicos, e esses foram claramente beneficiados com a emancipação política. A instauração do período republicano brasileiro está densamente vinculada à passagem da hegemonia britânica para a norte-americana.

Palavras-chave: Brasil. Economia política dos Sistemas-Mundo. Periferia. Semiperiferia.

\section{ABSTRACT}

The present study intends to demonstrate that the analysis of the Political Economy of the World-Systems (PEWS) has significant contributions a reflection of the current Brazilian reality. The PEWS develops its approach from the systemic perspective, whose basic elements are: a long-term historical analysis; interdisciplinarity; the interrelations between political, economic, social and cultural aspects; and the international division in center, semiperiphery and periphery. The main purpose of the article is to make explicit that our history over five centuries is of subordination to the interests of the center of capitalist accumulation. Although the center has been moving over these centuries, the peripheral condition most of the time and semiperiphery in shorter temporal durations persists. The traditional view of history, though often attempting to seek the interests of capital in the relations between the Iberians and colonies / ex-colonies, did not allow a more comprehensive look at this historical reality. In turn, PEWS's approach innovates the analysis of Brazilian history, showing, for example, the interrelations between: the "Great Navigations" and the hegemony of Italian cities; colonization and Dutch interests; British political emancipation and business; the establishment of the Brazilian republican period and the transition from British hegemony to North American.

Keywords: Brazil. Political economy of World-Systems. Periphery. Semiperiphery. 


\section{INTRODUÇÃO}

O presente estudo pretende demonstrar que a análise da Economia Política dos Sistemas-Mundo (EPSM) tem contribuições significativas para pensarmos a história do Brasil. A EPSM desenvolve sua abordagem a partir da perspectiva sistêmica, a qual tem por elementos basilares: uma análise histórica de longa duração; a interdisciplinaridade; as inter-relações entre os aspectos políticos, econômicos, sociais e culturais; e a divisão internacional em centro, semiperifeira e periferia.

Todos esses elementos são fundamentais para o estudo das estruturas históricas brasileiras, principalmente as desigualdades sociais e instabilidades políticas que perseveram na longa duração. Outro aspecto que se destaca nessa abordagem, no caso brasileiro, é a história de cinco séculos na condição de subordinação aos interesses do centro de acumulação capitalista. Muito embora o centro venha se deslocando ao longo desses séculos, a condição de periferia, na maior parte do tempo, e de semiperiferia, em durações temporais mais curtas, persistiu.

A história tradicional, embora muitas vezes tenha tentado buscar as relações e inter-relações entre os interesses do capital e o Brasil, não possibilitou um aprofundamento da afinidade dessa realidade histórica. Por sua vez, a abordagem da EPSM tem uma contribuição substancial para aprofundar as análises.

Nesse sentido, uma síntese da história do Brasil demonstrará o seu entrelaçamento com a economia-mundo capitalista. O percurso aqui apresentado busca demonstrar que o Brasil nasce, aos olhos europeus, na conjuntura da gênese da economia-mundo capitalista, sob a hegemonia das cidades italianas. Entretanto, a colonização empreendida por Portugal foi atrelada de forma visível aos interesses holandeses. Posteriormente, a coroa portuguesa conectou-se aos negócios britânicos, e esses foram claramente beneficiados com a emancipação política. Já a instauração do período republicano brasileiro está densamente vinculada à passagem da hegemonia britânica para a norte-americana. E as longas ditaduras que caracterizam sua república, pouquíssimo democrática, se imbricaram com os interesses do capitalismo central. Assim, a história do Brasil será revisitada para evidenciar seu entrelaçamento com os interesses da acumulação de capitais centrais, o que resultou em sua condição atual de semiperiferia.

\section{ECONOMIA POLÍTICA DOS SISTEMAS-MUNDO}

A EPSM vem se desenvolvendo desde a década de 70 do século XX, tendo como autores fundamentais o historiador Fernand Braudel, os cientistas sociais Immanuel Warllerstein e Giovanni Arrighi, dentre outros. De seus princípios, são fundamentais para o percurso a ser desenvolvido aqui: os conceitos de sistema histórico e de longa duração; as relações entre a esfera política e econômica; e a postura metodológica interdisciplinar. 


\title{
Gestãoe Desenvolvimento
}

A abordagem é sistêmica ${ }^{1}$, exatamente por Wallerstein analisar o capitalismo como um sistema social histórico.

\begin{abstract}
A expressão "sistema histórico" não costuma ser usada nas ciências sociais. Na verdade, em geral, a maioria dos cientistas sociais a consideraria anômala. Os que enfatizam o histórico minimizam em larga medida ou negam o sistêmico. Os que enfatizam o sistêmico normalmente ignoram o histórico. Não que, na qualidade de questão abstrata, não se reconheça a importância de reconciliar essa dicotomia [...]. [...] na prática tem havido forte pressão institucional para seguir numa ou na outra direção daquilo que, no final do século XIX, foi chamado de o Methodenstreit entre as formas idiográfica e nomotética de saber acadêmico no domínio da vida social (WALLERSTEIN, 2006, p. 265).
\end{abstract}

Wallerstein (2006) procurou resolver a dicotomia entre histórico e sistêmico observando a realidade social enquanto sucessão de mudanças e permanências interagindo simultaneamente sobre estruturas históricas de longa duração, como indicado por Braudel.

A longa duração braudeliana é considerada primordial, pois permite a observação histórica de processos em sua totalidade. Os estudos dentro dessa perspectiva buscam articular as diferentes durações temporais: a curta (fatos), a média (conjuntura) e a longa duração (estruturas históricas), para compreender, nos processos históricos, os elementos que facilitam ou dificultam as mudanças e as permanências. Observam-se, portanto, as várias velocidades das mudanças históricas.

Para Wallerstein, os Estados surgem dentro de um conjunto, o sistema interestatal, na mesma conjuntura da gênese do capitalismo histórico. O sistema capitalista requer uma relação muito particular entre os produtores econômicos - cadeias mercantis - e os que detêm o poder político - Estados nacionais. (WALLERSTEIN, 2005, p. 32).

A EPSM, ao abordar a questão da interdisciplinaridade, não a trata como um mero discurso, mas como um arcabouço metodológico, à qual Wallerstein refere-se como condição necessária para se pensar o social. A simples soma de várias ciências sociais não é suficiente dada a complexidade da realidade social. Além disso, ao se referir aos limites dos paradigmas do século XIX, sugere um degrau acima e recomenda a unidisciplinaridade como fundamento metodológico para o que ele nomeia como "ciências históricas". "A análise dos sistemas-mundo conclamava a uma reformatação drástica do marco intelectual das ciências

\footnotetext{
${ }^{1}$ Nesse sentido, há de ressaltar que o uso dessa expressão se dá pelo nível de autonomia e pelo funcionamento seguindo sua própria lógica; também por possuir limites temporais, ou seja, tem começo e fim - caso contrário, não seriam históricos; e por último, percebermos que todos os sistemas históricos expressam limites espaciais que podem se alterar conforme sua lógica de ação. Veremos mais adiante como esta postura teórico-metodológica pode oferecer novas bases para uma análise inovadora das RI no contexto contemporâneo (VIEIRA, 2016).
} 
sociais, convocando para uma reorganização unidisciplinar" (WALLERSTEIN, 2012, p. 27). Assim, resulta-se numa perspectiva que associa aspectos políticos, econômicos, sociais e culturais no processo histórico. A especialização científica desencadeada no século XIX contribuiu para novos conhecimentos, porém dificultou a visão do todo, e essa se tornou uma necessidade contemporânea.

Deve-se também destacar que de Braudel vem uma concepção específica de capitalismo. Para ele, o capitalismo caracteriza-se por grandes transações comerciais e financeiras, em que o capital é dotado de mobilidade e flexibilidade, com uma liberdade de escolha que está acima das regras da economia de mercado. O esforço capitalista é, portanto, para ultrapassar fronteiras e limites do próprio mercado - nem sempre ocorrendo de forma linear e progressiva -, atingindo, assim, suas metas globais de maximização de lucros. Braudel encara a emergência e a expansão do capitalismo como absolutamente dependentes do poder estatal. "O capitalismo só triunfa quando se identifica com o Estado, quando é o Estado" (BRAUDEL, 1995, p. 64).

Para os capitalistas, Estados soberanos são importantes por vários aspectos:

1] Os estados impõem as regras sobre a troca das mercadorias, do capital e do trabalho, e em que condições podem cruzar suas fronteiras. 2] Criam as leis concernentes aos direitos de propriedade dos estados. 3] Criam as regras concernentes ao emprego e à compensação dos empregados. 4] Decidem os custos que as companhias devem assumir. 5] Decidem que tipo de processos econômicos devem ser monopolizados, e até que ponto. 6] Cobram impostos. 7] Por último, quando as companhias estabelecidas dentro de suas fronteiras vierem as ser afetadas, podem usar seu poder no exterior para influenciar as decisões de outros estados (WALLERSTEIN, 2005, p. 68).

Observa-se, então, a importância fundamental do Estado para a acumulação de capitais. "A relação entre os estados com as empresas é a chave para o entendimento do funcionamento de uma economia-mundo capitalista." (Idem, p. 69). Apesar do discurso ideológico de não interferência, os empresários recorrem ao Estado para atingir seus objetivos.

Também é o Estado que oculta as trocas desiguais, ou seja, a própria estrutura da economia-mundo capitalista, na separação aparente entre a área econômica e a área política.

[...] os processos de acumulação do capitalismo levaram à sua concentração geográfica [...]; visto que a troca desigual responsável por ela fora possível graças à existência de um sistema interestatal composto por estados hierarquizados; e visto que as máquinas estatais tinham poder de alterar as operações do sistema [...] (WALLERSTEIN, 1985, p. 51).

Também cabem aos Estados soberanos as facilidades para a transnacionalidade das cadeias mercantis. Outra característica da economia-mundo capitalista é a coincidência da concentração de capitais no 
centro com estados fortes, pois a importância do Estado também é observável na criação de vantagens monopolistas. Assim, pode-se afirmar que cabe aos Estados a interferência nas cadeias mercantis, na regulação ou ausência dela nas questões relativas ao trabalho e ao capital em geral. Ou seja: "A homogeneidade nacional no interior duma heterogeneidade internacional é a fórmula duma economia-mundo” (WALLERSTEIN, p. 343).

E o equilíbrio de poder é consequência da rivalidade interestatal. Pois certa estabilidade decorre do acordo entre os membros para garantir que não haja um Estado que possa alcançar seus objetivos na arena internacional sem o aceite de vários outros membros. No moderno sistema-mundo capitalista, os Estados centrais têm buscado uma hegemonia. E cada um deles foi capaz, por algum tempo, "[...] de estabelecer as regras do jogo no sistema interestatal, em dominar a economia-mundo (na produção, comércio e finanças), em obter seus objetivos políticos com o uso mínimo da força militar [...]” (WALLERSTEIN, 2005, p. 83).

[...] o que impulsionou a prodigiosa expansão da economia mundial capitalista nos últimos quinhentos anos [...] não foi a concorrência entre os Estados como tal, mas essa concorrência aliada a uma concentração cada vez maior do poder capitalista no sistema mundial como um todo (ARRIGHI, 1996, p. 13).

Paralelamente a esse processo, ocorreu a hierarquização do sistema-mundo capitalista em centro / periferia / semiperiferia.

Os estados fortes servem aos interesses de alguns grupos e prejudicam os de outros. No entanto, do ponto de vista do sistema mundial como um todo, se tem que existir uma multidão de entidades políticas (isto é, se o sistema não é um império-mundo), então não pode dar-se o caso de que todas estas entidades sejam igualmente fortes. Porque se o fossem, estariam em condições de bloquear o funcionamento efectivo [sic] de entidades econômicas transnacionais cujo centro estivesse noutro estado. [...]

Isto implica então que a economia-mundo desenvolve um modelo em que as estruturas do Estado são relativamente fortes nas áreas do centro e relativamente fracas na periferia (WALLERSTEIN, p. 343).

E também

Os estados, como temos realçado, existem dentro do quadro de um sistema interestatal, e sua força relativa não é apenas o grau em que podem exercer sua autoridade no interior, como também o grau em que podem manter suas cabeças no alto, no competitivo meio do sistema-mundo (WALLERSTEIN, 2005, p. 80). 
Os Estados mais fortes vinculam-se com os mais débeis, pressionando-os para que mantenham suas fronteiras abertas ao fluxo dos fatores de produção, úteis às empresas centrais; para que se adaptem às suas necessidades políticas e para que aceitem suas práticas culturais, mas que não ajam com reciprocidade em nenhum dos casos (WALLERSTEIN, 2005, p. 80).

A articulação entre os dois subsistemas do sistema-mundo capitalista - o político e o econômico, ou seja, o sistema interestatal e as cadeias mercantis - atribui aos Estados o papel de facilitar a implementação de estruturas econômicas, políticas, sociais e culturais para o desenvolvimento do capitalismo. A abordagem da EPSM oferece uma compreensão abrangente das contradições e, principalmente, das relações entre os vários sujeitos históricos.

A proposta aqui apresentada busca penetrar um pouco na história do Brasil em primeiro lugar e a de Portugal, consequentemente, para observar os vínculos com os interesses de acumulação de capitais centrais.

Para a análise desse processo histórico, devemos voltar a 1415, quando Portugal ocupa Ceuta no norte da África. Entretanto, o enlaçamento de Portugal aos interesses do capital precede esse feito. Desde o século anterior, sobretudo no que tange à produção do vinho do Porto, sua liberdade econômica fora contida pelos investimentos ingleses na produção de seu produto mais característico. Assinala-se, assim, o lugar ocupado por Portugal na economia-mundo, antes mesmo da grande empreitada marítima. Mas para o desenvolvimento da análise aqui empreendida, faz-se necessário conhecer as motivações para a expansão territorial da Europa e porque Portugal a protagonizou.

A história de Portugal é muito singular se comparada com outras regiões, mesmo europeias. A Lusitânia nasce unificada, já que o Condado Portucalense se torna o Reino de Portugal em 1139 e tem suas fronteiras definidas em 1297. Também sua geografia Ihe atribuiu particularidades; por um lado sua posição - a costa atlântica e o sul mediterrânico - Ihe atribui grande vantagem, por outro, um solo acidentado, montanhoso e pedregoso the permite cultivar em torno de apenas 25\% do território. Em conjunto, tais características impuseram uma estreita relação marítima precocemente. Seja para a pesca, seja para o comércio, o mar foi seu horizonte e sua sobrevivência desde os primórdios.

No século XV, as navegações - para o domínio de outras terras e de novas opções de caminhos para as regiões de interesse comercial, em especial 'as Índias' - interessavam à nobreza, aos comerciantes nacionais e estrangeiros. "No caso de Portugal, pareciam existir vantagens no "negócio das descobertas" para muitos grupos - para o Estado, para a nobreza, para a burguesia comercial (nacional e estrangeira), e inclusive para o semi-proletariado das cidades" (WALLERSTEIN, 1990, p. 58).

Para Wallerstein, é importante destacar que as motivações para a expansão territorial eram europeias, e foi Portugal quem saiu na frente; e isso não foi por mero acaso. Os principais motivos eram os metais pre- 
ciosos, alimentos e combustível. E Portugal, dada sua condição marítima, foi a localidade mais apropriada.

Segundo ele, a Europa cristã e o mundo árabe mantinham uma relação comercial, em que a primeira cunhava prata, enquanto o segundo cunhava ouro. Devido a um desequilíbrio nos preços, a prata passou a sair da Europa sem que fosse compensada pela importação de ouro. Não importando qual fosse o caso "[...] a oferta não acompanhava a procura, e a pesquisa do ouro pela via marítima [...] foi inquestionavelmente um argumento para os primeiros navegadores portugueses" (WALLERSTEIN, 1990, p. 48). A essa altura, os metais preciosos eram os principais instrumentos de circulação monetária para o funcionamento do comércio na Europa.

A Europa Ocidental no século XV precisava também de alimentos e combustível. A conquista da África do Norte, das ilhas do Atlântico, bem como a expansão para a Europa Oriental, ajudou a fornecer os produtos que o ocidente europeu necessitava. Mais trigo e açúcar, e depois chocolate e bebidas, como o rum, completaram a dieta europeia. Outra necessidade era a madeira utilizada principalmente como combustível, mas também para construção naval e civil. Inicialmente, a Europa encontrou uma fonte considerável nas florestas do Norte, nas planícies mediterrânicas, e já no século XVI, a área báltica passou a exportar consideráveis quantidades de madeira para a Península Ibérica, Inglaterra e Holanda.

Outro fundamento importante para analisarmos o entrelaçamento do Brasil e de Portugal à economia-mundo capitalista é o conceito de Ciclo Sistêmico de Acumulação, de Giovanni Arrighi. ${ }^{2}$

Giovanni Arrighi retoma os percursos de Braudel e Wallerstein. No livro O longo século XX (1994), reconstrói o processo histórico das economias-mundo e retrata o ciclo norte-americano como produto dos ciclos precedentes. Ele apresenta os quatro Ciclos Sistêmicos de Acumulação (CSAs): Genovês - do século XV ao início do XVII; Holandês - do fim do século XVI até grande parte do XVIII; Britânico - segunda metade do século XVIII e início do XX; e Norte-americano - do fim do século XIX até hoje. Segundo ele, os CSAs são unidades de análise mais "manejáveis", construídas a partir das contribuições braudelianas, sobretudo o conceito de capitalismo como um processo histórico de longa duração e enquanto o terceiro andar da economia.

Os Ciclos Sistêmicos de Acumulação derivam

[...] diretamente da ideia braudeliana do capitalismo como a camada superior "não especializada" da hierarquia do mundo do comércio. Nessa camada superior é que se fazem os "lucros em larga escala". Nela, os lucros não são grandes apenas porque a camada capitalista "monopoliza" as atividades econômicas mais lucrativas; mais importante ainda é o fato de que a camada capitalista tem a flexibilidade necessária para deslocar conti-

\footnotetext{
${ }^{2}$ O trecho a seguir é parte do artigo "O Brasil e a economia-mundo capitalista: histórias entrelaçadas", apresentado no X Colóquio Brasileiro em Economia Política dos Sistemas-Mundo. UFSC, outubro de 2016.
} 
nuamente seus investimentos das atividades econômicas que estejam enfrentando uma redução dos lucros para as que não se encontrem nessa situação (ARRIGHI, 1996, p. 8).

Arrighi também esclarece que ao decompor esses cinco longos séculos em quatro CSAs - Gênova, Holanda, Grã Bretanha e Estados Unidos - refere-se "[...] ao sistema como um todo, e não a seus componentes". E também explica que concentrar-se "[...] nas estratégias e estruturas dos agentes governamentais e empresariais genoveses, holandeses, britânicos e norte-americanos deve-se exclusivamente à posição central que ocupam, de forma sucessiva, na formação dessas etapas" (ARRIGHI, 1996, p. 11).

O principal objetivo do conceito de ciclos sistêmicos é descrever e elucidar a formação, consolidação e desintegração dos sucessivos regimes pelos quais a economia capitalista mundial se expandiu, desde seu embrião subsistêmico do fim da Idade Média até sua dimensão global da atualidade (1996, p. 10).

A observação de expansões materiais, seguidas de expansões financeiras reiteradas vezes, levou à concepção dos Ciclos Sistêmicos de Acumulação. Ou seja, cada ciclo passou inicialmente por uma fase de intensificação de sua acumulação pela produção e/ou circulação e, em seguida, parte significativa de sua acumulação deslocou-se para a esfera financeira.

Também deve-se destacar que os Ciclos Sistêmicos de Acumulação consecutivos se superpõem parcialmente. Quando o "antigo" ciclo entra na fase financeira - ou seja, as taxas de lucratividade pendem para os negócios financeiros, o que causa um deslocamento dos investimentos de capitais para esse setor - o "novo" ciclo começa a se desenhar a partir de uma expansão material - o que pode ser por causa de novos produtos, por exemplo - e lentamente começa a atrair investimentos. (ARRIGHI, 1996, p. 6). A fase de transição de um CSA para outro apresenta simultaneamente a sucessão e a superposição parcial dos Ciclos Sistêmicos de Acumulação; quando ocorre a expansão financeira do CSA em vigor, começa concomitantemente uma nova expansão material que poderá constituir-se em um novo CSA.

O aspecto principal do perfil temporal do capitalismo histórico aqui esquematizado é a estrutura semelhante de todos os séculos longos. Todos esses constructos consistem em três segmentos ou períodos distintos: (1) um primeiro período de expansão financeira [...], no correr do qual o novo regime de acumulação se desenvolve dentro do antigo, sendo seu desenvolvimento um aspecto integrante da plena expansão e das contradições deste último; (2) um período de consolidação e desenvolvimento adicional do novo regime de acumulação [...], no decorrer do qual seus agentes principais promovem, monitoram e se beneficiam da expansão material de toda a economia mundial; e (3) um segundo período de expansão financeira, no decorrer do qual as contradições do regime de acumulação plenamente desenvolvido criam espaço para o surgimento de regimes concorrentes e 
alternativos, um dos quais acaba por se tornar [...] o novo regime dominante (ARRIGHI, 1996, p. 219-220).

Nessa perspectiva, outra característica do capitalismo consiste na flexibilidade e liberdade de escolha do capital, que o leva a um movimento de incremento na produção ou na financeirização de acordo com as taxas de lucro. Isso explica por que quando a "[...] expectativa é sistematicamente frustrada, o capital tende a retornar às formas mais flexíveis de investimento - acima de tudo, à sua forma monetária." O que indica essa expansão financeira? "[...] um sintoma da maturidade de determinado desenvolvimento capitalista” (Ibid., p. 5).

Essa tendência evidencia-se desde a Itália do século XV,

[...] quando a oligarquia capitalista genovesa passou das mercadorias para a atividade bancária, e na segunda metade do século XVI, quando os nobili vecchi genoveses, fornecedores oficiais de empréstimos ao rei da Espanha, retiraram-se gradualmente do comércio. Seguindo os holandeses, essa tendência foi reproduzida pelos ingleses no fim do século XIX e início do século XX, quando o fim da 'fantástica aventura industrial' criou um excesso de capital monetário. E depois da igualmente fantástica aventura do chamado fordismo-keynesianismo, o capital dos Estados Unidos tomou um rumo semelhante nas décadas de 1970 e 1980. (Ibid., p. 5).

A observação de expansões materiais, seguidas de expansões financeiras reiteradas vezes, levou à concepção dos Ciclos Sistêmicos de Acumulação.

A história dos quatro Ciclos Sistêmicos de Acumulação coincide com a história do Brasil. A proposta aqui é demonstrar que, de fato, não temos uma coincidência, mas um entrelaçamento.

Com estes pressupostos conceituais estabelecidos por Braudel, Wallerstein e Arrighi, pode-se analisar aspectos da história econômica do Brasil numa abordagem sistêmica.

\section{O ENTRELAÇAMENTO DO BRASIL À ECONOMIA-MUNDO CAPITALISTA}

\subsection{O CICLO SISTÊMICO DE ACUMULAÇÃO GENOVÊS}

Segundo Arrighi, o capitalismo desenvolveu-se originarialmente em Gênova, do século XV ao início do $\mathrm{XVII}$.

[...] o capitalismo genovês do século XV desenvolveu-se por um caminho que divergiu radicalmente do de todas as outras cidades-Estados italianas. Em graus diferentes e de diferentes maneiras, o capitalismo milanês, veneziano e florentino vinha-se desenvolvendo 
no sentido da gestão do Estado e de estratégias e estruturas cada vez mais "rígidas" de acumulação de capital. O capitalismo genovês, em contraste, moveu-se em direção à formação do mercado e as estratégias e estruturas de acumulação cada vez mais "flexíveis" (1996, p. 113).

As transformações decorrentes da compressão das redes genovesas de comércio de longa distância pelo "[...] fechamento da rota centro-asiática de Gênova para a China, o ataque do poder otomano, veneziano e catalão-aragonês ao comércio de Gênova no Mediterrâneo [...]", levou ao emprego de seu capital excedente e "[...] transformou os banqueiros mercantis genoveses na mais poderosa classe capitalista da Europa do século XVI" (Idem, p. 118-119).

E a Península Ibérica foi o lugar que ofereceu as melhores perspectivas para o capital genovês. A localização geográfica estratégica, o acesso a variadas mercadorias e o apoio em proteção pelos reinos católicos dada à situação religiosa conflitante do período. O intenso vínculo genovês/espanhol pode ser avaliado, por exemplo: "Em 1519, o poder do capital genovês já era de tal ordem que lhe permitiu desempenhar um papel crucial na eleição de Carlos V, então rei da Espanha, ao trono de imperador [...]” (Idem, p. 126).

Os financistas genoveses administraram um elo sistêmico significativo: o suprimento português de especiarias asiáticas, desviado para Sevilha pela presença incalculável de prata americana sob o domínio espanhol, lhes permitiu assumirem o controle do câmbio da moeda e dos seguros marítimos (ARRIGHI, 1996, p. 124-127), atividade significativa em época de Grandes Navegações e obviamente atribuindo a eles a gerência da economia-mundo.

A colonização da América do Sul empreendida por Portugal, sobretudo a partir de 1530, com a divisão e organização das terras em Capitanias Herditárias, e em 1549 com a implantação do Governo Geral, se articula à conjuntura do CSA genovês e à sua lógica de mercadorias/metais e ao controle da economia-mundo.

O modelo de colonização, implantado por Portugal para viabilizar sua participação nessa economia e a proteção dessas terras, teve como base o tripé: produção em larga escala, concentração das terras e trabalho escravo. Segundo Ferlini, tratou-se da empresa açucareira, pelas facilidades oferecidas e pelos lucros potenciais.

A produção de açúcar foi solução amplamente justificável: Portugal já possuía experiência em sua produção, desenvolvida no século anterior nas ilhas do Atlântico; dispunha de contatos comerciais que permitiam a alocação do produto no mercado europeu; seu relacionamento com o mundo financeiro de então, principalmente com banqueiros genoveses e flamengos, abria-lhe linhas de crédito para investimentos básicos; o Brasil possuía terras em abundância e o açúcar poderia ser produzido em larga escala (FERLINI, 2003, p. 20). 
Destaque para dois aspectos: relações comerciais para a vazão da produção, o que significa acordos com os genoveses; e relações com banqueiros genoveses e flamengos, o que demonstra Portugal articulado ao centro financeiro predominante e a outro que está em construção, como será visto mais à frente.

O modelo latifundiário e escravista da empresa açucareira implantada atende aos interesses da economia-mundo e a lógica da acumulação de capitais.

\begin{abstract}
Surgindo em seu sentido mercantil juntamente com o processo de acumulação de capitais, a produção de açúcar aparecia como "naturalmente" possível apenas em grande escala, carecendo de braço escravo e de largas porções de terra. O capital mercantil ao dedicar-se à produção açucareira, estruturou-se sob a forma de grande exploração, o que requereu a adoção de uma forma de trabalho específica: o trabalho escravo, capaz de impedir a exploração desse ramo de negócio por pequenos produtores. O sentido mesmo da necessidade de escravos estava na racionalização extensiva da produção. Produzir com escravos era produzir mais, excluíndo os produtores não escravistas: a produção escravista em larga escala dependia de grandes extensões de terra para sua expansão, que requeria mais e mais escravos (FERLINI, 2003, p. 32).
\end{abstract}

Assim a escravidão, inicialmente indígena e depois africana, garantiu a produção em larga escala e baixo custo.

Também Wallerstein analisa o processo de escravização no mundo colonial. Segundo ele, no período de construção histórica do capitalismo, a divisão mundial do trabalho era composta por diferentes formas de organização e controle do trabalho: escravatura, servidão e trabalho assalariado coexistiram para atender aos interesses da acumulação incessante de capital e foram distribuídas segundo a lógica hierárquica do próprio sistema. As regiões que detinham as atividades mais lucrativas e que ao mesmo tempo conseguiam manter relativo domínio sobre processos econômicos externos representavam o centro da economia-mundo capitalista. Por outro lado, as áreas em condições de trabalho compulsório, que produziam apenas os produtos de interesse dos agentes do centro, representavam a periferia do sistema. O que é o caso do Brasil colonial, seguramente.

Foram necessárias certas condições para que a mão de obra escrava fosse usada neste primeiro estágio do capitalismo. Primeiramente, o trabalho escravo não podia ser usado na produção de qualquer mercadoria, ainda mais se esta exigisse maiores técnicas de trabalho. Por isso a escravatura se mostrou rentável e eficaz para a produção agrícola de açúcar no Brasil e mais tarde de algodão na América do Norte. Outro aspecto importante consiste no fato de que as populações nativas da América foram sendo extintas com grande rapidez, tanto pelas armas metropolitanas, como pelas doenças e pela exaustão do trabalho compulsório. 0 declínio demográfico mostrou-se acentuado nestas regiões, exigindo novas fontes de mão-de-obra. 


\begin{abstract}
A Nova Espanha (México) sofreu uma quebra dramática na sua população, que passou de cerca de 11 milhões em 1519 para cerca de 1,5 milhões por volta de 1650. O Brasil e o Peru parecem ter sofrido um declínio igualmente dramático. [...] num momento relativamente precoce, os espanhóis e portugueses desistiram de tentar recrutar índios como escravos no hemisfério ocidental e começaram a depender exclusivamente da importação de africanos para as plantações trabalhadas por escravos. Presumivelmente, o custo de transporte não eleva ainda os custos a um ponto mais alto do que o potencial custo de evitar as fugas da população indígena remanescente. Para além do mais, esta última estava a morrer rapidamente (WALLERSTEIN, 1990, p. 94).
\end{abstract}

O comércio, assim com o transporte dos escravos africanos, foram inicialmente realizados por portugueses, no entanto, passaram para as mãos dos holandeses, ingleses, etc., constituindo-se num elemento importante para a acumulação de capitais. Os elementos apontados aqui buscam demonstrar que o modelo colonial implantado pelos portugueses na sua colônia americana - o Brasil - almejou sua própria inserção na economia-mundo capitalista gerida pelos genoveses.

Pedro Vieira defende a tese de que Portugal, apesar de seu protagonismo e precocidade nas grandes navegações e no comércio ultramarino, não conseguiu avançar para posições mais privilegiadas da economia-mundo capitalista. Pelo contrário, se no século XVI, Portugal

[...] colabora para, e se beneficia do surgimento da economia-mundo, situando-se próximo ao centro, no século seguinte, enquanto se intensificava a lógica capitalista na economia-mundo e surgiam estados nacionais muito poderosos, em Portugal, tanto nos negócios públicos quanto nos privados prevaleciam instituições pré-capitalistas. Como resultado, porvolta de 1650, [...] a condição de quase-Estado e de uma economia fundada na escravidão colocavam Portugal - e sua colônia americana - na condição de periferia da economia-mundo (2012, p. 212).

Importante, ainda, ressaltar que esse modelo colonial impôs uma estrutura fundiária densamente concentradora, a partir das Capitanias Hereditárias, tornando-se uma estrutura histórica da sociedade brasileira que ainda hoje determina as relações sociais, econômicas, políticas e de trabalho. A concentração de terras e a prolongada escravidão tornaram-se características imperativas ao longo do processo histórico do Brasil. Muitas vezes, ao tratar-se desses temas, há a tendência de que seja visto como decorrência dos interesses portugueses exclusivamente. Contudo, ao se ampliar o foco, observa-se uma relação entre os aspectos de ordem global, ou seja, interesses de ordem sistêmica, com o modelo de exploração implantado nessa colônia, é o caso dos latifúndios e da escravidão. 


\subsection{O CICLO SISTÊMICO DE ACUMULAÇÃO HOLANDÊS}

Como se viu anteriormente, Arrighi (1996) observa que a característica de uma fase de transição de um Ciclo Sistêmico para outro é a financeirização do Ciclo descendente. Isso ocorreu na transição entre o CSA Genovês e o Holandês, cujo período estendeu-se do fim do século XVI até a grande parte do XVIII, "A expansão financeira do fim do século XVI e início do século XVII também se associou a uma escalada das lutas intercapitalistas e interterritorialistas [...]" (ARRIGHI, 1996, p. 130).

Diante do acirramento dos conflitos "[...] a comunidade mercantil holandesa estava singularmente posicionada para explorar esse crônico desequilíbrio temporal e espacial entre demanda e oferta." (Idem, p. 137). A Holanda, ao conquistar o comércio regional e global, e o poder da Bolsa de Amsterdam, assumiu o controle da liquidez, a "[...] centralização das transações e da especulação com mercadorias [...]" (Idem, p. 142).

Uma característica significativa do CSA Holandês consistiu na formação das Companhias de Comércio e o nível de organização e racionalidade empreendidas por elas.

[...] as companhias de comércio e navegação holandesas eram, a um tempo, beneficiárias e instrumentos da contínua centralização do comércio e das altas finanças mundiais em Amsterdam: beneficiárias, porque essa centralização lhes garantia o acesso privilegiado a mercados lucrativos para a colocação de seus produtos e a fontes econômicas onde obter seus insumos, inclusive mercados ou fontes para se desfazer do capital excedente ou obtê-lo, dependendo de seu estágio de desenvolvimento e das oscilações de seu patrimônio. Mas elas também foram instrumentos poderosos de expansão global das redes comerciais e holandesas, sendo possível exagerar, sob esse ponto de vista, seu papel na estratégia global de acumulação dos holandeses. (Idem, p. 143).

Para se observar o nível de entrelaçamento da economia colonial brasileira/portuguesa ao CSA Holandês e às suas companhias de comércio, pode-se remeter ao estudo empreendido por Pedro Vieira (2010). Ele demonstrou o papel fundamental dos holandeses na cadeia mercantil do açúcar produzido no Brasil no período (1550-1800). O comércio/escambo de escravos africanos, o refino e distribuição do açúcar na Europa e o transporte de escravos e mercadorias foram atividades lucrativas desenvolvidas pelos holandeses. Por exemplo, Pedro Vieira, citando Postma: "[...] por volta de 1622, os estaleiros holandeses estavam construindo anualmente quinze navios somente para comércio com o Brasil” (VIEIRA, 2010, p. 518). O que indica a intensidade do comércio realizado com a colônia portuguesa.

A pesquisa de Pedro Vieira indica a função dos holandeses na cadeia mercantil do açúcar desde meados do século XVI. Exatamente quando se inicia a produção açucareira em larga escala, os interesses comuns entre portugueses e flamengos se intensificam e aumentam progressivamente. Enquanto os lusitanos se en- 


\section{Gestãoe Desenvolvimento}

carregavam da etapa produtiva na colônia, os flamengos pegavam o produto bruto em Lisboa, refinavam e distribuíam pela Europa. (VIEIRA, 2010, p. 518).

[...] as refinarias holandesas trabalhavam com produto brasileiro, que tramitava por Portugal rumo à Antuérpia e posteriormente Amsterdã. [...] Do lado de cá interessaria a exportação do produto melhor acabado, tendo, portanto, maior valor agregado. Do lado metropolitano - a Holanda era a metrópole indireta da economia açucareira brasileira - interessaria importar açúcar bruto (VIEIRA, 2010, p. 519).

Segundo Vieira, após a ocupação de Recife pela Companhia das Índias Ocidentais em 1630, os holandeses passaram a se envolver diretamente no comércio de escravos. "[...] o controle holandês era tão grande na Costa da Mina que para negociar escravos aí, os comerciantes baianos precisam pagar uma licença equivalente a 10\% do valor das mercadorias que seriam trocadas por cativos" (VIEIRA, 2010, p. 513).

Assim, o Brasil tem um lugar significativo e indiscutível no processo de acumulação holandês. Mercadorias - como açúcar e escravos -, fornecimento de navios, todas são atividades altamente lucrativas, sob o domínio dos holandeses e de sua capacidade de monopolizá-los. A presença holandesa no Brasil foi também física. Mais conhecida pelas invasões no nordeste em 1624, e de 1630 a 1654, mas também pelos comerciantes em outras regiões do país. Caio Prado Jr lembra:

Encontraremos, ainda em fins do séc. XVII e princípios do seguinte, alguns mercadores estrangeiros estabelecidos no Brasil; um dos principais bairros do Rio de Janeiro ainda conserva até hoje o nome de Flamengo, de uma colônia de comerciantes daquela origem lá instalados (PRADO JR., 1994, p. 53).

A capacidade de superar monopólio pela 'livre concorrência' é certamente a inovação empreendida pelos britânicos na construção de sua ascensão.

Durante todo o século XVIII, Londres ganhou terreno em relação a Amsterdam como centro rival de altas finanças. Isso resultou dos sucessos britânicos na luta com a França e com concorrentes menores pelo controle exclusivo do comércio com o mundo extra-europeu, bem como da transferência do excedente de capital holandês para empresas britânicas. (ARRIGHI, 1996, p. 163). 


\title{
3.3 O CICLO SISTÊMICO DE ACUMULAÇÃO BRITÂNICO
}

Esse CSA abarcou o período da segunda metade do século XVIII e início do XX. A expansão material britânica calcada na produção de bens de capital, máquinas, ferrovias e produtos industrializados a faz chegar ao século XIX como a promotora de uma

\begin{abstract}
[...] contínua liberalização unilateral do comércio britânico criou condições para uma grande expansão do comércio e da produção mundiais. Os bens de capital britânicos encontraram uma demanda imediata entre as organizações governamentais e empresariais do mundo inteiro. E essas organizações, por sua vez, aumentaram sua produção de insumos primários para venda na Grã-Bretanha, a fim de obter os recursos necessários para pagar pelos bens de capital ou amortizar as dívidas contraídas quando de sua aquisição (ARRIGHI, 1996, p. 165).
\end{abstract}

O entrelaçamento da colônia portuguesa com o processo histórico de ascensão britânico já se evidencia pelo atrelamento de Portugal com a economia e a política da Inglaterra, mesmo antes de sua condição hegemônica. Na conjuntura da Era Napoleônica e da disputa pela hegemonia que se seguiu, Portugal ficou do lado inglês, recebendo deles proteção para a fuga da Família Real. Os custos dessa cobertura foram cobrados já na chegada do Príncipe Regente e demais membros da comitiva ao território brasileiro. Ainda em Salvador, ele decreta a Abertura dos Portos às Nações Amigas (1808), o que significou efetivamente livre comércio da colônia com os britânicos. Insuficiente para os interesses ingleses, em 1810 são assinados os Tratados Econômicos e Políticos, nos quais os produtos ingleses são privilegiados com taxas alfandegárias menores até mesmo que os produtos portugueses.

Esse tema é abordado por Pedro Vieira (2012) em seu artigo de forma muito clara. Na transição da hegemonia holandesa para a britânica,

[...] a submissão praticamente total de Portugal aos interesses ingleses revela que este país estava totalmente despreparado para aproveitar as novas oportunidades criadas pela [...] reorganização [da economia-mundo em novas bases]. Por isso, no decorrer dela, Portugal caiu para uma posição periférica [...](2012, p. 258).

O que confirma sua tese, de que Portugal foi incapaz de alcançar alguma ascensão econômica ou política na economia-mundo capitalista apesar de seu pioneirismo comercial e marítimo no século XVI. E isso pode ser observado em todos os CSAs, e mais explicitamente no britânico.

Registra-se a presença inglesa na economia brasileira ao longo de todo o século XIX: seja na venda de inúmeros produtos, ou de bens de capital como é o caso da construção das ferrovias, seja nos constantes 
empréstimos financeiros; e em questões de espectro social, como nas exigências pela abolição da escravatura3. Um nivel de detalhamento pode ser constatado pela cadeia mercantil do café.

Uma pesquisa realizada sobre a Cadeia Mercantil do Café, no período de 1830 a 19294, demonstrou que o envolvimento do comércio britânico - com mercadorias como: ferramentas e maquinários para infraestrutura para ferrovias, e também com capitais para a política de valorização do café ou do transporte marítimo - permitiu que os nódulos mais rentáveis dessa cadeia mercantil estivessem no centro do sistema-mundo. O modelo britânico beneficiou-se dessa commodity brasileira da mesma forma que os holandeses o fizeram com o açúcar. Os lucros mais significativos em ambos os casos ficaram com os setores localizados nos centros hegemônicos: seja pelos lucros com o transporte marítimo, ou na etapa final de produção (torrefação, moagem e embalagem no caos da produção cafeeira).

O processo de emancipação política do Brasil também ilustra de forma clara os laços de interesse britânico e sua participação efetiva: seja realizando o empréstimo necessário para o pagamento da indenização exigida por Portugal para assinar a independência - no valor de dois milhões de libras esterlinas ${ }^{5}$-, seja na participação nas batalhas (com o fornecimento de armas, uniformes e até mesmo de mercenários) que antecederam a assinatura do Tratado de Paz e Aliança em 1825 entre Portugal e Brasil. O Brasil independente tornou-se cativo econômico e financeiro do Império Britânico, impondo, desde 1808 e "[...] em toda a primeira metade do século [XIX], uma séria limitação à autonomia do governo brasileiro no setor econômico." (FURTADO, 1997, p. 93).

Os negócios financeiros no decorrer do século XIX se intensificaram e ultrapassaram a barreira secular, adentrando ao século XX. O financiamento da própria cadeia do café, a construção das ferrovias, modernizações urbanas e de portos, enfim foram empreendimentos que exigiram grandes investimentos. Mas são os interesses do café que aglutinam grande parte desses financiamentos, sobretudo no decorrer das políticas de valorização desse produto implementadas no Brasil.

Rosana Moraes afirma que,

[...] tendo percorrido de forma detalhada o encadeamento espacial do financiamento dos negócios do café no Brasil de 1850 a 1930, e examinando os diversos tipos e fontes de financiamentos que a cadeia mercantil do café demandou em cada nódulo, corroboramos

\footnotetext{
${ }^{3}$ Desde os Tratados de 1810, os britânicos exigiram a abolição da escravatura por seus interesses econômicos - como, por exemplo, o baixo custo da produção brasileira em comparação com a antilhana - travestidos de argumentos morais.

${ }^{4}$ VIEIRA, R. A cadeia mercantil do café produzido no Brasil entre 1830 e 1930. In: VIEIRA P. A.; VIEIRA, R.; FILOMENO, F. (Org.). O Brasil e
} - Capitalismo Histórico: passado e presente na Análise de Sistemas-Mundo. São Paulo: Editora Cultura Acadêmica, 2012. p. 265-296.

${ }^{5}$ Era exatamente esse o valor da dívida de Portugal com os banqueiros ingleses. 
o fato de que o financiamento da cadeia mercantil do café criou dependências mútuas entre o capital financeiro local a outros interesses econômicos localizados em outras partes do mundo, e que o capital estrangeiro interagiu com predominância no nódulo do financiamento da comercialização desta commodity, caracterizando assim o financiamento dos negócios do café como transnacional, e contribuindo para a consolidação da economia-mundo capitalista (MORAES, 2015, p. 118).

E também fortaleceu Londres como centro financeiro.

Outro exemplo fundamental das relações entre o Brasil e o CSA britânico são as ferrovias. Vinham das indústrias inglesas a maquinaria, as ferramentas e os projetos de engenharia, e ainda buscávamos os financiamentos para a sua construção ${ }^{6}$. No que tange à Cadeia Mercantil do café

\begin{abstract}
Ainda se faz necessário sublinhar o fato de que o domínio da exportação por empresas europeias e norte-americanas permitia-lhes o controle sobre o processo produtivo, o que reitera a posição periférica do Brasil na economia-mundo capitalista. Assim, no período estudado, apesar de atingir a condição de maior produtor mundial de café e de este ser um produto com mercado consumidor crescente, não coube ao Brasil a parcela mais significativa dos lucros advindos (VIEIRA, 2012, p. 292).
\end{abstract}

O modelo britânico de "imperialismo de livre comércio" foi uma centralização sem precedentes do poder mundial nas mãos de um único Estado, o Reino Unido. Por outro lado, o imperialismo de livre comércio estabeleceu o princípio de que as leis que vigoravam dentro e entre as nações estavam sujeitas à autoridade superior do "mercado mundial" regido por "leis próprias". Esse poder resultou-se da adoção unilateral de uma prática e uma ideologia de livre comércio pelo Reino Unido. Ainda combinando a expansão territorial ultramarina com o desenvolvimento de uma indústria de bens de capital no país, essa política tornou-se um poderoso instrumento de governo de toda a economia mundial. Ao abrirem seu mercado interno, os governantes britânicos criaram redes mundiais que dependiam da expansão da riqueza e poder do Reino Unido, e de fidelidade a ela. Assim, pode-se dizer que o capitalismo mundial, sob a égide britânica, foi ao mesmo tempo um império mundial e uma economia mundial.

\footnotetext{
${ }^{6} \mathrm{O}$ crescente endividamento com os ingleses pode ser observado pelos dados apresentados por Caio Prado Jr, até 1852 era de 2,5 milhões de libras, no período até 1889 atinge a cifra de 60 milhões de libras (PRADO JR., 1994, p. 169).
} 
Como já foi apontado, capitais oriundos da circulação de mercadorias ${ }^{7}$, de bens duráveis e da esfera financeira ${ }^{8}$ foram carreados do Brasil ao centro da economia-mundo em larga escala. Isso se manteve da segunda metade do século XVIII até o fim do século XIX e início do XX, quando se forma a conjuntura de crise do CSA britânico.

Houve tentativas de resistência às pressões e interesses ingleses, sobretudo quando os lucros dos negócios das classes dominantes locais eram frontalmente atingidos, como é o caso da abolição da escravatura. Com as leis "para inglês ver" como a Lei de Proibição do Tráfico de Escravos (1831), a Lei do Ventre Livre (1871) e a Lei dos Sexagenários (1885), os brasileiros conseguiram postergar a abolição de 1808 até 1888 . Porém, a Guerra do Paraguai (1864-1870) demonstra de forma contundente a subserviência do Brasil aos interesses ingleses; e de várias maneiras, como a necessidade de novos empréstimos para as despesas da própria guerra e a derrota mutiladora do Paraguai, a qual também atendeu aos negócios do imperialismo da Inglaterra na região do Rio da Prata, abrindo-a inteiramente para as mercadorias e finanças britânicas (MOTA, 1995).

\subsection{O CICLO SISTÊMICO DE ACUMULAÇÃO NORTE-AMERICANO}

O Reino Unido exerceu as funções de governo mundial até o fim do século XIX. De 1870 em diante, começou a perder o controle e a Alemanha e os EUA iniciam sua disputa pela ascensão na economia mundial, o que resultará na hegemonia norte-americana até os dias atuais.

Os desafios alemão e norte-americano ao poderio mundial britânico fortaleceram-se mutuamente, comprometeram a capacidade da Grã-Bretanha de governar o sistema interestatal e acabaram levando a uma nova luta pela supremacia mundial, com uma violência e morbidez sem precedentes (ARRIGHI, 1996, p. 59).

Os EUA estavam numa posição muito melhor do que a Alemanha. Suas dimensões continentais, insularidade e dotação extremamente favorável de recursos naturais - bem como a política sistematicamente seguida por seu governo de manter as portas do mercado interno fechadas aos produtos estrangeiros, mas abertas ao capital, à mão de obra e à iniciativa do exterior - transformaram o país no maior beneficiário do imperialismo britânico de livre comércio. Além disso, a primeira e a segunda guerra mundial aceleraram o processo de hegemonia norte-americana.

\footnotetext{
${ }^{7}$ Dentre as mercadorias estão desde fósforos, sabão, caixões de defunto a bens de luxo como porcelanas, cristais, candelabros e lustres. 8 Os juros, nominalmente de 5\%, alcançavam assim, de fato, quase 10\%. Os banqueiros ingleses (foram quase sempre a casa Rothschild), conluiados com os desonestos altos dignatários [sic] do Império, lançavam-se sem piedade sobre esta presa inerme que era a nação brasileira (PRADO JR. 1994, p. 138).
} 
A partir de 1915, a demanda britânica de armamentos e máquinas somente pode ser atendida pelos EUA, o que thes deu direitos sobre as receitas e ativos britânicos. A expansão material norte-americana, iniciada por volta de 1870, é concomitante à expansão financeira britânica e à "Grande Depressão" (1873-1896).

Como todos os séculos anteriores, o longo século XX compõe-se de três seguimentos distintos. O primeiro começa na década de 1870 e se estende até 1930, isto é, desde a crise sinalizadora até a crise terminal do regime britânico de acumulação. O segundo vai da crise terminal do regime britânico até a crise sinalizadora do regime norte-americano - uma crise que podemos situar por volta de 1970. E o terceiro e último segmento vai de 1970 até a crise terminal do regime norte-americano (ARRIGHI, 1996, p. 220).

Com o fim da Segunda Guerra Mundial, os EUA haviam acumulado imensos créditos, que lhe davam o "monopólio da liquidez mundial". E mais, logo após a guerra, já estavam estabelecidos os principais contornos desse novo sistema mundial: em Bretton Woods foram estabelecidas as bases do novo sistema monetário internacional; em Hiroshima e Nagasaki, novos meios e métodos de violência; e com a Carta das Nações Unidas, as novas normas e regras de legitimação de poder.

O modelo norte-americano é assim caracterizado:

[...] o livre comércio ideologizado e praticado pelo governo dos Estados Unidos, em todo o período de seu predomínio hegemônico, tem sido, antes, uma estratégia de negociação intergovernamental - bilateral e multilateral - sobre a liberalização do comércio, visando basicamente abrir as portas das outras nações aos produtos e às empresas norte-americanos (ARRIGHI, 1996, p. 71).

E "[...] com isso, atingiu-se um grau muito mais amplo de livre comércio multilateral sob a hegemonia norte-americana, comparado ao da britânica” (Idem, p. 72). E o "livre comércio" garantiu privilégios aos EUA, uma vez que sendo mais produtivo e competitivo conquistou todos os mercados que lhes interessaram.

Outra característica do modelo norte-americano: as empresas multinacionais. Enquanto as Companhias de Comércio e Navegação dos séculos anteriores - presentes nos CSAs holandês e britânico - eram instrumentos altamente maleáveis da expansão do Estado; "[...] as empresas multinacionais do século XX não o são. Longe de serem tais instrumentos à disposição do poder estatal, estas empresas cedo transformaram-se no limite mais fundamental desse poder" (Idem, p. 317). Elas situam-se acima dos interesses estatais, deslocam-se na direção da melhor lucratividade, independentes das necessidades nacionais.

O Ciclo norte-americano imbricou-se com a história do Brasil de forma incontestável. Aqui destacaremos três aspectos fundamentais: a presença expressiva das multinacionais, a relação da guerra fria e a ditadura militar (1964-1985) e o significativo endividamento. 
No que tange às multinacionais, basta lembrar que o desenvolvimento econômico ${ }^{9}$ brasileiro - a partir dos anos 50 do século passado - caracterizou-se pelo protagonismo das indústrias multinacionais, sobretudo de bens de consumo e de bens duráveis; entre elas, a mais significativa foi a de automóveis. Nesse caso, além do produto propriamente, transladou-se conjuntamente o modelo automotivo: peças, pneus, rodovias e combustíveis. Esse levou, ao longo do tempo, à extinção do modelo ferroviário/britânico, substituído pelo modelo norte-americano, cujo ícone é o automóvel.

A transição hegemônica levou a uma substituição que

[...) não era só de um país, mudava-se também a natureza da presença estrangeira. Os capitais ingleses destinavam-se preferencialmente ao setor terciário (estradas de ferro, companhias de seguros, etc.) ou eram emprestados aos governos. Os capitais norte-americanos majoritariamente são aplicados em atividades produtivas, quer no setor secundário, quer no setor primário (MONTEIRO, 1990, p. 313).

Por isso a industrialização brasileira com capitais nacionais não se consolidou. No modelo britânico, a importação de produtos industrializados em massa fazia com que a balança comercial fosse muitas vezes negativa; já o modelo norte-americano chega com suas indústrias - em virtude do baixo custo da mão de obra, das matérias primas e dos impostos e taxas -, o que levou a um fluxo de capital para as sedes/matriz das indústrias transplantadas.

Outro aspecto a ser destacado do entrelaçamento do Brasil com os interesses dos CSA norte-americano é a relação entre a Guerra Fria, o Golpe de 1964 e a Ditadura que perdurou até 1985.

A conjuntura internacional da Guerra Fria - pós Segunda Guerra Mundial, em 1945, até 1991, com a extinção da União Soviética - marcou-se, pelas disputas estratégicas e conflitos indiretos entre os Estados Unidos da América e a União das Repúblicas Socialistas Soviéticas. Entre outras características, ocorreu a divisão dos diversos países em dois grandes blocos políticos e econômicos, com a exigência de cada país "escolher" o lado com o qual manterá relações econômicas e políticas, bem como a necessidade de explicitar internacionalmente sua posição.

[...] a Guerra Fria: 1) estabilizou o "equilíbrio de poder" internacional, deslocando as esferas de choque para a oposição entre os dois sistemas, conformando os conflitos e rivalidades da política mundial; 2) forjou um novo sistema internacional, cuja lógica articulou as relações entre as nações; 3) constitui-se num conflito ideológico que, propagando-se através da mídia, atingiu culturalmente a sociedade e sua conduta; 4) forçou uma corrida

\footnotetext{
${ }^{9}$ Ver sentido específico de desenvolvimento econômico na periferia do sistema-mundo. ARRIGHI, CF. A ilusão do desenvolvimento. Trad. Sandra Guardini Teixeira Vasconcelos. Petrópolis: Vozes, 1997.
} 
armamentista, que criou um complexo industrial militar continuamente produtivo, que tendeu a buscar mercados nos conflitos convencionais localizados do Terceiro Mundo; 5) consequentemente, serviu como elemento incentivador de tais conflitos; e 6) inaugurou a era nuclear e a possibilidade de destruição global da humanidade (HEIN, p. 1).

A Guerra Fria instaurou o medo, sobretudo do comunismo, que suportou a alcunha de anticristão e a personificação do mal a ser combatido à custa de vidas, de sonhos. No Brasil, o golpe civil militar de 1964 possui vários fatores e interpretações. Uma delas

[...] não deve ser minimizada, fala, por sua vez, da Grande Conspiração, da aliança entre grupos sociais conservadores brasileiros - a exemplo de empresários, latifundiários, políticos reacionários, militares golpistas e Igreja tradicionalista - com a CIA e o Departamento de Estado norte-americano. A conspiração direitista interna - externa, desse modo, teria sido o fator fundamental para a crise política de 1964 (FERREIRA, 2003, p. 345).

Durante a Ditadura Militar brasileira, a luta contra o comunismo teve um viés político autoritário e intransigente, e um viés econômico que endividou o país.

Consolidado o regime ditatorial a partir de 1968 - ou seja, debelada a ação das forças sociais e políticas que se opunham ao capital estrangeiro, elevada a taxa de juros e iniciada a reanimação da economia -, os capitais estrangeiros, impulsionados pela formação de capitais excedentes no centro, principalmente sob a forma de eurodólares, voltaram a adentrar agressivamente na economia brasileira sob várias formas: a) sob a forma de investimento direto, elevaram-se de uma média anual de US\$ 54,2 milhões em 1962-1966 para uma de US\$ 106 milhões em 1967-1970; b) sob a forma de empréstimos e financiamentos, cresceram de uma média anual de US\$318,8 milhões no primeiro período para uma de US\$ 714 milhões no segundo (SOUZA, 2014, p. 338).

Nilson A. Souza comenta ainda que a forma dos investimentos diretos

[...] não se deu, necessariamente, pela instalação de nova capacidade produtiva pelas empresas estrangeiras. Ao contrário, sua raiz principal é a aquisição de empresas brasileiras por empresas estrangeiras. Uma evidência disto é que, entre 1966 e 1970, 52\% das transnacionais estadunidenses que se estabeleceram no país o fizeram mediante compra de empresas locais (das quais mais de $80 \%$ eram nacionais); essa cifra se elevou a $61 \%$ no período de 1971-1973 (SOUZA, 2014, p. 339).

O "milagre brasileiro" (1968-1973) - caracterizado pelo crescimento do PIB e por grandes construções, principalmente - elevou a dívida externa brasileira de 4 para 12 bilhões de dólares. O entrelaçamento econô- 
mico da ditadura militar brasileira com o modelo norte-americano foi amalgamado pelo endividamento. 0 processo de abertura/redemocratização chega quando a dívida externa já atingia US\$ 115,10 bilhões, "apesar de haverem sido transferidos para o exterior, sob a forma de juros, US\$150 bilhões de 1980 a 1989 [...]" (SOUZA, 2014. p. 368).

A acumulação de capitais no centro resultou da expropriação desta nação. Embora o "desenvolvimentismo" dos anos 50 e o "milagre econômico" dos anos 70 tenham elevado o Brasil à categoria de semiperiferia do sistema. O que pode ser interpretado em duas dimensões contraditórias: uma positiva - o país deixou de ser periferia do sistema, está mais próximo ao centro de acumulação de capital; outra negativa - o país passa a ser mais controlado pelo centro, uma vez que seus interesses são mais concretos, e quantitativamente observáveis.

Esse processo culminou na crise dos anos 90 pela condição de endividamento e na série de exigências norte-americanas liberalizantes da economia - conhecidas como Consenso de Washington - como a abertura mais profunda da economia, inclusive o amplo processo de privatizações.

Marcelo Arend analisou o desempenho da economia brasileira na dinâmica da economia-mundo ao longo do século XX. Segundo ele, seja na transição do CSA britânico para o norte-americano ou nas distintas fases desse último ciclo, a economia-mundo afetou profundamente a dinâmica da economia brasileira impondo-Ihe os limites e as possibilidades. Por isso no final do século, o Brasil figura "[...] como uma das economias mais internacionalizadas do mundo [...]", em que os interesses do capital financeiro governam o conjunto do sistema-mundo capitalista (AREND, 2013, p. 168).

\section{CONSIDERAÇÕES FINAIS}

De forma sintética e global, buscou-se aqui desenvolver elementos que demonstrem o entrelaçamento histórico da economia-mundo capitalista e o Brasil.

Em resumo: desde o início da colonização portuguesa, com a implantação da produção açucareira até o fim da condição colonial, os interesses centrais da economia-mundo capitalista nortearam a ocupação, a produção e a circulação de produtos, matérias-primas e mão-de-obra escrava, que se consistia também numa mercadoria. Isso impulsionou a acumulação de capitais nas regiões centrais significativamente.

A emancipação política, em 1822, não trouxe a independência consigo. O Brasil, atrelado aos interesses centrais, endividado e dependente de produtos e capitais, sobretudo britânicos, alçou a condição de nação subordinada e periférica.

Quando finalmente o país chega à república, o processo de modernização, submisso aos interesses norte-americanos, aufere e garante não somente a acumulação interna das classes dominantes, mas, sobretudo, a acumulação externa dos grupos centrais da economia-mundo capitalista. 
A abordagem da EPSM constitui-se, portanto, como instrumento indispensável para se compreender a inserção do Brasil de forma subjugada aos interesses do capitalismo histórico em detrimento das necessidades de sua população. Nesta ótica, quando se fala hoje em crise econômica brasileira e em desindustrialização nacional é o caso de se apontar muitas questões: A crise é local? Quando esse país foi "nacionalmente" industrializado? E a crise política atual está relacionada exclusivamente a questões de ordem nacional? Não há outros interesses internacionais envolvidos?

Seguramente, as transformações são muito mais globais; a crise atual é sistêmica e multidimensional. E uma das causas da crise no Brasil tem sido o deslocamento dos investimentos centrais para áreas mais lucrativas - sobretudo pelo baixo custo da mão-de-obra, impostos, taxas e custos - como é o caso da Ásia e da África. Assim, o que se observa globalmente é o resultado do esforço da economia-mundo capitalista de sobrevida diante do processo histórico de crise terminal do atual modelo, construído nos últimos quinhentos anos.

Portanto, analisar de forma estanque e isolada a situação do Brasil não é suficiente. Somente uma abordagem sistêmica pode realmente dimensionar a conjuntura atual e os elementos estruturais e históricos que se enredam. Os interesses hegemônicos se impuseram ao longo da história e oprimem a todos ainda.

\section{REFERÊNCIAS}

AREND, Marcelo. O Brasil e o longo século XX: condicionantes sistêmicos para estratégias nacionais de desenvolvimento. In: VIEIRA, R. (Org.). O Brasil, a China e os EUA na atual conjuntura da Economia-Mundo capitalista. Marília: Oficina Universitária; São Paulo: Cultura Acadêmica, 2013, p. 135-171.

ARRIGHI, Giovanni. O longo século XX: dinheiro, poder e as origens de nosso tempo. Trad. Vera Ribeiro. Rio de Janeiro: Contraponto; São Paulo: Editora UNESP, 1996.

BRAUDEL, Fernand. Civilização material, economia e capitalismo: séculos XV-XVIII. Trad. Telma Costa. São Paulo: Martins Fontes, 1995, vol 1.

FERLINI, Vera. Terra, trabalho e poder: o mundo dos engenhos no Nordeste colonial. Bauru: EDUSC, 2003.

FERREIRA, Marieta; PINTO, Surama. A crise dos anos 20 e a Revolução de 1930. In: FERREIRA, J. DELGADO, L. A. N. (Org.) O Brasil republicano: o tempo do liberalismo excludente: da Proclamação da República à Revolução de 1930. Rio de Janeiro: Civilização Brasileira, 2003, p. 387-415.

FURTADO, Celso. Formação econômica do Brasil. 26. ed. São Paulo: Companhia Editora Nacional, 1997. 
HEIN, Lothar. Guerra Fria: conceitos e problemas. Núcleo de Estudos Contemporâneos. Disponível em: <http://www.historia.uff.br/nec/sites/default/files/text10.pdf>. Acesso em: 13 jan. 2014.

MORAES, Rosana Isabel de. O Financiamento da Cadeia Mercantil do Café no Brasil de 1850 a 1930. Dissertação (Mestrado em Ciências Sociais) - Faculdade de Filosofia e Ciências, da Universidade Estadual Paulista - UNESP, Campus de Marília, 2015.

MOTA, Carlos Guilherme. História de um silêncio: a guerra do Paraguai (1864-1870). Estudos Avançados, a. 9, v. 24, 1995, p. 243-254. In: <http://www.scielo.br/pdf/ea/v9n24/v9n24a12.pdf>. Acesso em: 1 jul. 2016.

MONTEIRO, Hamilton de Mattos. Da República Velha ao Estado Novo. In: LINHARES, Maria Yeda (Org.). História Geral do Brasil. Rio de Janeiro: Editora Campus, 1990, p. 302-315.

PRADO JÚNIOR. Caio. História Econômica do Brasil. 41. ed. São Paulo: Brasiliense, 1994.

SOUZA, Nilson Araújo. A economia da ditadura e da transição. In: PINHEIRO, Milton (Org.). Ditadura: o que resta da transição. São Paulo: Boitempo, 2014, p. 331- 369.

VIEIRA, Pedro Antônio. A economia-mundo, Portugal e o "Brasil" no longo século XVI (1450-1650). In: VIEIRA P. A.; VIEIRA, R.; FILOMENO, F. (Org.). O Brasil e o Capitalismo Histórico: passado e presente na Análise de Sistemas-Mundo. São Paulo: Editora Cultura Acadêmica, 2012. p. 207-264.

. A inserção do "Brasil" nos quadros da economia-mundo capitalista no período 1550-c.1800: uma tentativa de demonstração empírica através da cadeia mercantil do açúcar. Economia e Sociedade, Campinas, v. 19, n. 3, v. 40, p. 499-527, 2010.

VIEIRA, Rosângela de Lima. Contribuições da EPSM para estudos nas Relações Internacionais. In: SALATINI, Rafael (Org.). Cultura e direitos humanos nas relações internacionais, vol. I: Reflexões sobre cultura, Marília, SP: Oficina Universitária; São Paulo: Cultura Acadêmica, 2016, p. 107-118.

. A cadeia mercantil do café produzido no Brasil entre 1830 e 1930. In: VIEIRA P. A.; VIEIRA, R.; FILOMENO, F. (Org.). O Brasil e o Capitalismo Histórico: passado e presente na Análise de Sistemas-Mundo. São Paulo: Editora Cultura Acadêmica, 2012, p. 265-296.

WALLERSTEIN, I. A análise dos sistemas-mundo como movimento do saber. In: VIEIRA, P.; VIEIRA, R. L.; FILOMENO, F. A. (Org.). O Brasil e o capitalismo histórico: passado e presente na análise dos sistemas-mundo. São Paulo: Cultura Acadêmica Editora, 2012, p. 17-28.

Impensar a ciência social. Os limites dos paradigmas do século XIX. Trad. Adail Sobral e Maria Stela Gonçalves. Aparecida: Ideias \& Letras, 2006. 
Análisis de sistemas-mundo. Una introducción. Trad. Carlos Daniel Schroeder. México: Siglo XXI, 2005.

O sistema mundial moderno: a agricultura capitalista e a origem da economia-mundo européia no século XVI. Afrontamento, 1990.

o Capitalismo histórico. Trad. Denise Bottmann. São Paulo: Brasiliense, 1985.

O moderno Sistema-Mundo. Trad. Carlos Leite, Fátima Martins e Joel Lisboa. Porto: Afrontamento. $\mathrm{s} / \mathrm{d}$. 